\title{
Effects of Leak Compensation on Patient-Ventilator Synchrony During Premature/Neonatal Invasive and Noninvasive Ventilation: A Lung Model Study
}

\author{
Taiga Itagaki MD, Christopher T Chenelle, Desmond J Bennett, Daniel F Fisher MSc RRT, and \\ Robert M Kacmarek PhD RRT FAARC
}

\begin{abstract}
BACKGROUND: During both nasal noninvasive ventilation (NIV) and invasive ventilation of neonates, the presence of air leaks causes triggering and cycling asynchrony. METHODS: Five ICU ventilators (PB840, PB980, Servo-i, V500, and Avea) were compared in available invasive ventilation and NIV ventilator modes (pressure control continuous spontaneous ventilation [PC-CSV] and pressure control continuous mandatory ventilation [PC-CMV]). The V500 and Avea do not provide PC-CSV and PC-CMV in NIV. The Servo-i and Avea were tested with and without their proximal flow sensor. The ASL 5000 lung model (version 3.5) was used to simulate 4 neonatal scenarios (body weight $0.5,1,2$, and $4 \mathrm{~kg}$ ). The ASL 5000 was ventilated via endotracheal tube (invasive ventilation) or nasal cannula (NIV) with 4 different leaks. RESULTS: The Avea (without flow sensor) during invasive ventilation and Servo-i and PB840 during NIV were not triggered by inspiratory efforts of the ASL 5000 at the baseline leak in the $0.5 \mathrm{~kg}$ scenario. In invasive ventilation, overall (median) asynchrony index was significantly lower with the PB980 (1\%) and V500 (3\%) than with the Servo-i (with flow sensor, 50\%; without flow sensor, $50 \%$ ) and Avea (with sensor, 50\%; without sensor, $62 \%$ ) $(P<.05$ for all comparisons). The PB840 (33\%) was significantly different from all ventilators $(P<.05)$. In NIV, the asynchrony index was significantly lower in PB980 (2\%) than in the Servo-i (with sensor, $100 \%$; without sensor, 100\%) and PB840 (75\%) $(P<.05$ for both). There was no difference in asynchrony index between PC-CSV and PC-CMV in all tested conditions and ventilators. CONCLUSIONS: The ability of leak compensation to prevent asynchronous breathing varied widely between ventilators and lung mechanics. The PB980 and V500 were the only two ventilators to acclimate to all leak scenarios in invasive ventilation, and PB980 was the only ventilator to acclimate to all leak scenarios in NIV. Key words: leak compensation; neonatal ventilation; acute care ventilator; invasive ventilation; noninvasive ventilation. [Respir Care 2017;62(1):22-33. () 2017 Daedalus Enterprises]
\end{abstract}

\section{Introduction}

The primary approach for supporting neonates with respiratory distress is nasal CPAP or noninvasive ventilation

\footnotetext{
The authors are affiliated with the Department of Respiratory Care, Massachusetts General Hospital, Boston, Massachusetts. Drs Itagaki and Kacmarek are also affiliated with the Department of Anesthesia, Critical Care and Pain Medicine, Massachusetts General Hospital, Harvard Medical School, Boston, Massachusetts.

This study was partially funded by a research grant from Covidien. Dr Kacmarek has disclosed relationships with Covidien, Venner Medical, and Orange Medical. The other authors have disclosed no conflicts of interest.

Dr Itagaki presented a version of this work at the American Association for Respiratory Care Congress 2015, held November 7-10, 2015, in Tampa, Florida.
}

(NIV). ${ }^{1}$ However, nearly half of all neonates supported with CPAP still require endotracheal intubation and invasive ventilation. ${ }^{2}$ NIV provides greater respiratory support than CPAP and prevents intubation in a large fraction of neonates who would otherwise fail CPAP. ${ }^{2,3}$

The major problem with neonatal patient-triggered NIV or invasive ventilation is air leak. ${ }^{4}$ The presence of air leak

\footnotetext{
Supplementary material related to this paper is available at http:// www.rcjournal.com.

Correspondence: Robert M Kacmarek PhD RRT FAARC, Department of Anesthesia, Critical Care, and Pain Medicine, Massachusetts General Hospital, Harvard Medical School, 55 Fruit Street, Boston, MA 02114. E-mail: rkacmarek@mgh.harvard.edu.
}

DOI: $10.4187 /$ respcare.04825 
interferes with the ability of the ventilator to respond to patients' spontaneous breathing efforts and causes triggering and cycling asynchrony. ${ }^{5,6}$ Asynchronous patient-ventilator interactions increase the work of breathing and the duration of mechanical ventilation. ${ }^{7,8}$ This is true not only for NIV, but also for neonatal invasive ventilation due to the use of uncuffed endotracheal tubes.

\section{See the Related Editorial on Page 135}

Manufacturers have implemented leak compensation algorithms on the latest acute care ventilators. In adult and pediatric settings, we previously conducted bench studies demonstrating that these leak compensation algorithms improve triggering and cycling synchronization. ${ }^{9}, 10$ However, to the best of our knowledge, there have been no assessments of leak compensation during premature/neonatal ventilation using a digital lung simulator. Recently, Vignaux et $\mathrm{al}^{11}$ performed a neonatal lung model study that compared the abilities of 4 neonatal and 6 adult ventilators to trigger, pressurize, and cycle in both the absence and presence of leaks during invasive ventilation and NIV. The focus of these comparisons was more on ventilation performance than leak compensation, and the leak compensation algorithm was activated only during NIV. The auto-triggering they observed was primarily solved by slight adjustment of trigger sensitivity and the use of NIV algorithms. Our study is the first comprehensive assessment of leak compensation algorithms during premature/neonatal invasive ventilation and NIV in terms of prevention of asynchronous events. Previously, we compared the performance of all-age ICU ventilators with that of the Babylog 8000 Plus (Dräger, Lübeck, Germany) and concluded that all ICU ventilators tested were able to perform equally to the neonatal ventilator. ${ }^{12}$ Thus, we evaluated all-age ICU ventilators in this study. The aim of this bench study is to evaluate the ability of leak compensation algorithms in all-age ICU ventilators equipped with an NIV mode to prevent asynchronous breathing in the presence of leaks during premature/neonatal patient-triggered invasive ventilation and NIV.

\section{Methods}

Five all-age ICU ventilators (Servo-i [Maquet, Wayne, New Jersey], PB840 [Covidien, Mansfield, Massachusetts], PB980 [Covidien], Evita Infinity V500 [Dräger, Lübeck, Germany], and Avea [CareFusion, San Diego, California]) (Table 1) were compared, using an ASL 5000 lung simulator (version 3.5, IngMar Medical, Pittsburgh, Pennsylvania) with increasing and decreasing system leaks. Different gas leaks were created by sets of 3-way stopcocks (Discofix, B. Braun Medical, Bethlehem, Pennsylvania) placed between an endotracheal tube/nasal cannula and the

\section{QUICK LOOK}

\section{Current knowledge}

During neonatal ventilation, leaks can cause triggering and cycling asynchrony, a key element of success with patient-triggered ventilation. Different neonatal ventilators demonstrate significant differences in their ability to compensate for leaks and achieve patient-ventilator synchrony.

\section{What this paper contributes to our knowledge}

All-age ICU ventilators demonstrated huge variations in leak compensation performance during both invasive and noninvasive ventilation. Ventilator performance, patient size, and leak volume are all important determinants of appropriate triggering and cycling of breaths.

lung simulator (Fig. 1). Each ventilator was connected to the lung simulator by a standard neonatal corrugated circuit (Neonatal Breathing Circuit, Hudson RCI-Teleflex, Morrisville, North Carolina). All of the ventilators were studied with a dry circuit.

\section{Lung Model and Study Setup}

The lung simulator was used to simulate 4 neonatal ventilation scenarios, with different lung sizes and mechanics estimated based on body weight $(0.5,1,2$, and 4 $\mathrm{kg})$. The breathing frequency, resistance, and compliance; the maximum inspiratory pressure drop $\left(\mathrm{P}_{\max }\right)$; the airway occlusion pressure $\left(\mathrm{P}_{0.1}\right)$; and the inspiratory time with the time percentages for the pressure drop (inspiratory), pressure maintenance (hold), and relaxation (expiratory) in each scenario are summarized in Table 2. We applied a short hold in inspiratory effort to obtain predefined $\mathrm{P}_{0.1}$ because the ASL 5000 cannot set $\mathrm{P}_{\max }$ and $\mathrm{P}_{0.1}$ separately without using an end-inspiratory hold (see Figure S1 in the supplementary materials available at http://www.rcjournal. com). We set compliance and resistance values for each model by reviewing previous neonatal bench studies ${ }^{11-15}$ as well as clinical studies of lung function tests in preterm infants, ${ }^{16-21}$ specifically using individual references for each weight group: $0.5 \mathrm{~kg},{ }^{17,18} 1 \mathrm{~kg},{ }^{19} 2 \mathrm{~kg},{ }^{20}$ and $4 \mathrm{~kg}^{21}$ (compliance varying from 0.5 to $5 \mathrm{~mL} / \mathrm{cm} \mathrm{H}_{2} \mathrm{O} / \mathrm{kg}$; resistance varying from 50 to $\left.350 \mathrm{~cm} \mathrm{H}_{2} \mathrm{O} / \mathrm{L} / \mathrm{s}\right)$. We calculated resistance values of each endotracheal tube/nasal cannula by using pressure drop across the interface measured with the PTS 2000 (Mallinckrodt, Dublin, Ireland) and average peak flow during invasive ventilation and NIV, and we confirmed that total respiratory resistances were within the range that we estimated for each model (Table 2). We used a $\mathrm{P}_{\max }$ smaller than the reported esophageal pressure change 
Table 1. Specifications for Neonatal Use of Mechanical Ventilators Tested

\begin{tabular}{|c|c|c|c|c|c|}
\hline Ventilator & Software & $\begin{array}{c}\text { Leak } \\
\text { Compensation }\end{array}$ & $\begin{array}{c}\text { Flow Trigger } \\
\text { Sensitivity }\end{array}$ & $\begin{array}{l}\text { Inspiratory } \\
\text { Rise Time }\end{array}$ & $\begin{array}{l}\text { Expiratory Trigger Setting } \\
\% \text { of Inspiratory Flow } \\
\text { (PC-CSV) }\end{array}$ \\
\hline Servo-i & V6.01.02 & $\begin{array}{l}20 \mathrm{~L} / \mathrm{min} \text { (invasive); } \\
25 \mathrm{~L} / \mathrm{min} \text { (NIV); } \\
15 \mathrm{~L} / \mathrm{min} \text { (nasal CPAP) }\end{array}$ & $\begin{array}{l}0-100 \% \text { (fraction of } \\
\text { bias flow) }\end{array}$ & $0-0.2 \mathrm{~s}$ & $\begin{array}{l}1-70 \% \text { (invasive); } \\
10-70 \% \text { (NIV) }\end{array}$ \\
\hline PB840 & $\mathrm{AK}$ & $10 \mathrm{~L} / \mathrm{min}$ & $0.1-10 \mathrm{~L} / \mathrm{min}$ & $1-100 \%$ & $1-80 \%$ \\
\hline PB980 & $\mathrm{K}$ & $15 \mathrm{~L} / \mathrm{min}$ & $0.1-10 \mathrm{~L} / \mathrm{min}$ & $1-100 \%$ & $1-80 \%$ \\
\hline V500 & 02.41 & $30 \mathrm{~L} / \mathrm{min}$ & $0.2-15 \mathrm{~L} / \mathrm{min}$ & $0-2 \mathrm{~s}$ & $1-80 \%$ \\
\hline Avea & 4.4 & ND & $0.1-20 \mathrm{~L} / \mathrm{min}$ & $1-9$ & $5-45 \%$ \\
\hline \multicolumn{6}{|c|}{$\begin{array}{l}\text { PC-CSV }=\text { pressure control continuous spontaneous ventilation } \\
\text { NIV }=\text { noninvasive ventilation } \\
\text { ND }=\text { no data }\end{array}$} \\
\hline
\end{tabular}

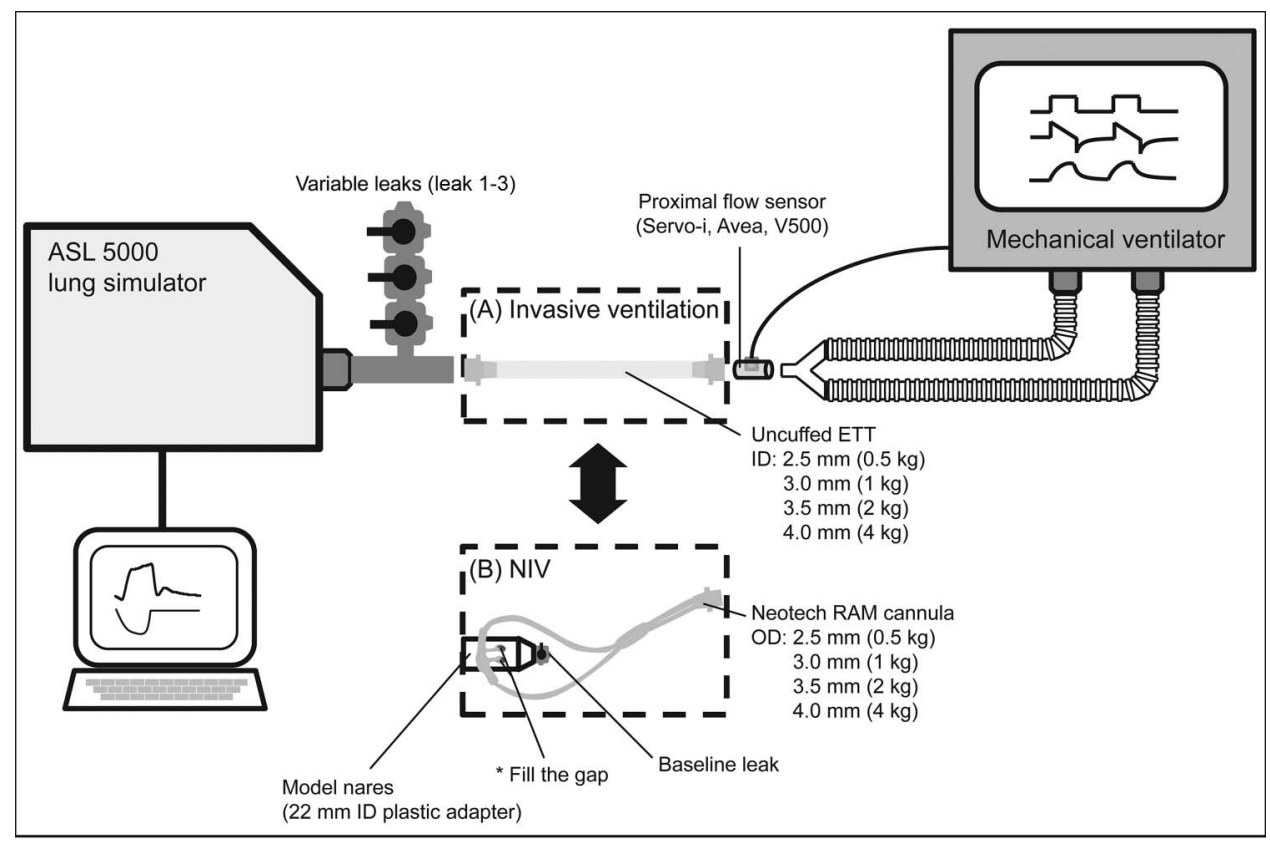

Fig. 1. The equipment outside the dashed frames was used in common for both invasive and noninvasive ventilation. A: Setup for invasive ventilation. B: Setup for noninvasive ventilation (NIV). ETT = endotracheal tube; ID = inner diameter; OD = outer diameter.

of normal neonates ${ }^{22}$ because inspiratory efforts in children vary between awake and asleep, ${ }^{23-25}$ especially in critically ill premature infants. ${ }^{11,26}$

In invasive ventilation modes, the ventilators were directly affixed to the lung model with uncuffed endotracheal tubes $(2.5-\mathrm{mm}$ internal diameter for $0.5 \mathrm{~kg}, 3.0-\mathrm{mm}$ internal diameter for $1 \mathrm{~kg}, 3.5$-mm internal diameter for 2 $\mathrm{kg}$, and $4.0-\mathrm{mm}$ internal diameter for $4 \mathrm{~kg}$ ). The tip of the endotracheal tube was cut vertically and tightly connected to a common airway to establish a baseline leak of $0 \mathrm{~L} / \mathrm{min}$ (Fig. 1A). Three intentional leak levels (leak 1, leak 2, and leak 3) were set to $0.3,0.6$, and $0.9 \mathrm{~L} / \mathrm{min}$ for 0.5 and $1 \mathrm{~kg}$ and to $0.6,1.2$, and $1.8 \mathrm{~L} / \mathrm{min}$ for 2 and $4 \mathrm{~kg}$. To obtain these leak levels, the flow pump mode of the ASL 5000 was used. We adjusted each orifice of the stopcock opening until the pressure was constant at $5 \mathrm{~cm} \mathrm{H}_{2} \mathrm{O}$ when flow was at the selected leak level. We also investigated the pressure-flow characteristics of each leak level (see supplementary Figure S3). We chose these leak settings higher than clinically reported ${ }^{27,28}$ but within the claims of the manufacturers (Table 1) because our aim was to evaluate the maximum ability of leak compensation algorithms of each ventilator. All 6 combinations of increasing leak change (baseline leak $\rightarrow$ leak 1 , baseline leak $\rightarrow$ leak 2 , baseline leak $\rightarrow$ leak 3 , leak $1 \rightarrow$ leak 2 , leak $1 \rightarrow$ leak 3 , leak $2 \rightarrow$ leak 3 ) and all 6 combinations of decreasing leak change (leak $3 \rightarrow$ leak 2 , leak $3 \rightarrow$ leak 1 , leak $3 \rightarrow$ baseline leak, leak $2 \rightarrow$ leak 1 , leak $2 \rightarrow$ baseline leak, leak $1 \rightarrow$ baseline leak) were evalu- 


\section{Leak Compensation in ICU Ventilators During Neonatal Ventilation}

Table 2. Lung Model Setup Used With ASL 5000 During Invasive and Noninvasive Ventilation

\begin{tabular}{|c|c|c|c|c|}
\hline Scenario & $0.5 \mathrm{~kg}$ & $1 \mathrm{~kg}$ & $2 \mathrm{~kg}$ & $4 \mathrm{~kg}$ \\
\hline Frequency, breaths/min & 70 & 60 & 50 & 40 \\
\hline Compliance, $\mathrm{mL} / \mathrm{cm} \mathrm{H}_{2} \mathrm{O}$ & 0.5 & 1 & 2 & 5 \\
\hline $\mathrm{P}_{\max }, \mathrm{cm} \mathrm{H}_{2} \mathrm{O}$ & -3.0 & -4.0 & -5.0 & -6.0 \\
\hline $\mathrm{P}_{0.1}, \mathrm{~cm} \mathrm{H}_{2} \mathrm{O}$ & -2.1 & -2.8 & -3.5 & -4.2 \\
\hline Unassisted tidal volume, $\mathrm{mL}$ & 0.9 & 3.2 & 7.8 & 23.2 \\
\hline Inspiratory time, $\mathrm{ms}$ & 250 & 300 & 350 & 400 \\
\hline Increase, $\%$ & 24.2 & 20.0 & 17.0 & 13.5 \\
\hline Hold, \% & 5.0 & 10.0 & 12.2 & 13.2 \\
\hline Release, $\%$ & 19.5 & 20.0 & 19.5 & 17.8 \\
\hline Pause, \% & 0 & 0 & 0 & 0 \\
\hline $\mathrm{FRC}, \mathrm{mL}$ & 12.5 & 25 & 50 & 100 \\
\hline \multicolumn{5}{|l|}{ Resistance, $\mathrm{cm} \mathrm{H}_{2} \mathrm{O} / \mathrm{L} / \mathrm{s}$} \\
\hline \multicolumn{5}{|l|}{ Invasive ventilation } \\
\hline $\begin{array}{l}\text { Inspiratory/expiratory resistance } \\
\text { of the ASL } 5000\end{array}$ & 200 & 150 & 100 & 50 \\
\hline Resistance of ETT & 60.2 & 33.4 & 18.5 & 13.7 \\
\hline $\begin{array}{l}\text { Estimated total respiratory } \\
\text { resistance during invasive } \\
\text { ventilation }\end{array}$ & 260.2 & 183.4 & 118.5 & 63.7 \\
\hline \multicolumn{5}{|l|}{ NIV } \\
\hline $\begin{array}{l}\text { Inspiratory/expiratory resistance } \\
\text { of the ASL } 5000\end{array}$ & 200 & 150 & 100 & 50 \\
\hline Resistance of RAM cannula & 27.8 & 27.8 & 22.6 & 23.9 \\
\hline $\begin{array}{l}\text { Estimated total respiratory } \\
\text { resistance during NIV }\end{array}$ & 227.2 & 177.8 & 122.6 & 73.9 \\
\hline $\begin{array}{l}\text { Estimated total respiratory resistance is equal t } \\
\text { resistance of the interface (endotracheal tube fo } \\
\text { noninvasive ventilation). } \\
\mathrm{P}_{\text {max }}=\text { maximum inspiratory pressure drop } \\
\mathrm{P}_{0.1}=\text { the airway occlusion pressure } 0.1 \mathrm{~s} \text { after } \\
\text { FRC = functional residual capacity } \\
\mathrm{ETT}=\text { endotracheal tube } \\
\text { NIV = noninvasive ventilation }\end{array}$ & $\begin{array}{l}\text { the sum of } \\
\text { invasive ve } \\
\text { he start of }\end{array}$ & $\begin{array}{l}\text { ng model' } \\
\text { ilation, RA } \\
\text { spiratory fl }\end{array}$ & $\begin{array}{l}\text { resistance } \\
\text { M cannula }\end{array}$ & \\
\hline
\end{tabular}

ated. Leak levels were varied in a manner to evaluate all combinations of increasing and decreasing leaks, because in our pilots, ${ }^{9}, 10$ we noted that the ability of a ventilator to compensate for leaks differed based on the direction of the leak change as well as the magnitude of the leak change.

In the NIV modes, a nasal cannula (RAM, Neotech, Valencia, California) was used for NIV.13,29 The nasal cannula was affixed to the model nares using a 22-mm inner diameter plastic adapter (Adapter 962-E, Unomedical, McAllen, Texas). The size of the nasal cannula was selected as follows: "micro preemie" (2.5-mm outer diameter) for $0.5 \mathrm{~kg}$, "preemie" (3.0-mm outer diameter) for 1 $\mathrm{kg}$, "newborn" (3.5-mm outer diameter) for $2 \mathrm{~kg}$, and "infant" (4.0-mm outer diameter) for $4 \mathrm{~kg}$. The gap between the nasal cannula and drilled nostrils was filled with a sealant to prevent leak to ensure that a specifically defined and reproducible leak was produced, although this is not the usual clinical practice (Fig. 1B). A baseline leak of $0.5 \mathrm{~L} / \mathrm{min}$ at a constant airway pressure of $5 \mathrm{~cm} \mathrm{H}_{2} \mathrm{O}$ was established by adjusting the valve attached to the model nares for all models. Leak 1, leak 2, and leak 3 were set to $1,1.5$, and $2 \mathrm{~L} / \mathrm{min}$ for the 0.5 and $1 \mathrm{~kg}$ models and to 2 , 3 , and $4 \mathrm{~L} / \mathrm{min}$ for the 2 and $4 \mathrm{~kg}$ models. We chose these leak settings based on leak compensation claims of the manufacturers. All 6 combinations of increasing leak change and all 6 combinations of decreasing leak change described for invasive ventilation were evaluated.

\section{Ventilator Settings}

During invasive ventilation, all ventilators were tested in both pressure control continuous spontaneous ventilation (PC$\mathrm{CSV}$ ) and pressure control continuous mandatory ventilation (PC-CMV) modes. ${ }^{30}$ The Servo-i and Avea were tested both with and without their proximal flow sensor, since its use is optional. The V500 was always tested with its proximal flow sensor in accordance with manufacturer's instructions. Inspiratory pressure above PEEP was set to establish a baseline tidal volume of $6 \mathrm{~mL} / \mathrm{kg}$, and PEEP was set at $5 \mathrm{~cm} \mathrm{H}_{2} \mathrm{O}$. Flow trigger sensitivity, when adjustable, was set to be as sensitive as possible while avoiding auto-triggering at baseline leak. Inspiratory rise time was set to the fastest setting in all ventilators evaluated. Leak compensation was activated if available. During PC-CSV, termination criteria were set at a level to obtain total inspiratory time of the ventilator $\left(\mathrm{T}_{\mathrm{I}_{\mathrm{vent}}}\right.$; time from the start of effort to the moment the ventilator cycled from inspiration to exhalation) equal to $\pm 20 \%$ of the inspiratory time of the simulator $\left(\mathrm{T}_{\mathrm{I}_{\mathrm{sim}}}\right.$; increase [\%] plus hold [\%] in the effort model). PC-CMV was evaluated in both active breathing (spontaneous triggering of the ventilator) and passive breathing (controlled ventilation during apneic conditions). The inspiratory time setting was $250,300,350$, and $400 \mathrm{~ms}$ for the $0.5,1,2$, and $4 \mathrm{~kg}$ models, respectively, to equal $\mathrm{T}_{\mathrm{I}_{\mathrm{sim}}}$. The ventilator frequency was set at $35,30,25$, and 20 breaths/min during active breathing and at 70, 60, 50 , and 40 breaths/min during passive breathing for the 0.5 , 1,2 , and $4 \mathrm{~kg}$ models, respectively. The definitions of 3 inspiratory times $\left(\mathrm{T}_{\mathrm{I}_{\mathrm{vent}}}, \mathrm{T}_{\mathrm{I}_{\mathrm{sim}}}\right.$, and inspiratory time) are shown in the supplementary materials (Figure S1).

During the NIV assessment, the Servo-i, PB840, and PB980 were tested in both PC-CSV and PC-CMV modes. The V500 and Avea were excluded from this part because they do not support PC-CSV or PC-CMV in neonatal NIV. Inspiratory pressure above PEEP was set to establish a baseline tidal volume of $6 \mathrm{~mL} / \mathrm{kg}$. In each mode, PEEP, flow trigger sensitivity, rise time, termination criteria, and inspiratory time were set the same as during invasive ventilation. Leak compensation was activated if it was available. During PC-CMV, the inspiratory time setting was 250, 300, 350, and $400 \mathrm{~ms}$ for the $0.5,1,2$, and $4 \mathrm{~kg}$ models, respectively, to equal $\mathrm{T}_{\mathrm{I}_{\mathrm{sim}}}$. The ventilator frequency was $35,30,25$, and 20 breaths/min for the $0.5,1,2$, and 4 $\mathrm{kg}$ models, respectively. 
Apnea backup ventilation was activated, and the apnea interval was set at $20 \mathrm{~s}$. If backup ventilation was activated, we immediately reset the ventilator and waited for spontaneous recovery because the criteria of automatic return from backup ventilation differed between ventilators.

\section{Data Collection and Evaluation}

Before data gathering, we waited up to 2 min for the simulator to consistently trigger the ventilator during baseline leak. If triggering was not achieved, the evaluation was defined as a non-run, considered unable to compensate, and further leaks and data were not collected. If triggering was established, all combinations of increasing and decreasing leaks were sequentially added to the system (baseline leak $\rightarrow$ leak $1 \rightarrow$ leak $2 \rightarrow$ leak $3 \rightarrow$ leak $1 \rightarrow$ leak $3 \rightarrow$ leak $2 \rightarrow$ leak $1 \rightarrow$ baseline leak $\rightarrow$ leak $2 \rightarrow$ baseline leak $\rightarrow$ leak $3 \rightarrow$ baseline leak). Two minutes of data after each change in leak level were collected and analyzed. The global asynchrony index $x^{4,31-33}$ was calculated as follows: Asynchrony index $(\%)=$ [auto-triggering + double-triggering + ineffective efforts + premature cycling + delayed cycling during $2 \mathrm{~min} /$ (total simulated breaths + auto-triggering) $] \times 100$.

Synchronization was defined as triggering without auto-triggering, double-triggering, ineffective efforts, premature cycling, and delayed cycling. Asynchrony events were detected by visual inspection of flow and airway pressure recordings. Asynchrony events were defined according to previous studies ${ }^{4,31-33}$ :

- Auto-triggering: a cycle delivered by the ventilator in the absence of a signal generated by the lung simulator;

- Double-triggering: 2 ventilator-delivered cycles separated by a very short expiratory time occurring within a single inspiratory effort of the lung simulator;

- Ineffective efforts: inspiratory effort of the lung simulator not followed by a ventilator-delivered cycle;

- Delayed cycling: a cycle normally triggered by the ventilator but with $\mathrm{T}_{\mathrm{I}_{\mathrm{vent}}}$ greater than twice the $\mathrm{T}_{\mathrm{I}_{\mathrm{sim}}}$;

- Premature cycling: a cycle normally triggered by the ventilator but with $\mathrm{T}_{\mathrm{I}_{\mathrm{vent}}}$ less than one-half the $\mathrm{T}_{\mathrm{I}_{\mathrm{sim}}}$.

When backup ventilation operated, simulated breaths during backup ventilation were counted as ineffective efforts.

Additionally, 5 consecutive, normally triggered breaths $>1$ min after the change of the leak were analyzed for (1) triggering delay time (ms): the time from the beginning of the inspiratory effort to the time of the maximum negative airway pressure deflection needed to trigger the ventilator, (2) peak flow (L/min), (3) peak pressure $\left(\mathrm{cm} \mathrm{H}_{2} \mathrm{O}\right)$, and (4) expiratory $\mathrm{V}_{\mathrm{T}}(\mathrm{mL})$.

\section{Statistical Analysis}

Data were collected by the lung simulator software (ASL 3.5 ), and each breath was manually analyzed to count asynchronous events. Non-run assumed that ineffective efforts occurred in all simulated breaths. Results are expressed as mean values $\pm \mathrm{SD}$ or medians with interquartile ranges, depending on the data distribution. A one-way analysis of variance with the Tukey honest significant difference post hoc test was used for parametric data, and the Kruskal-Wallis one-way analysis by ranks and the Dunn test for multiple comparisons were used for non-parametric data. Statistical analysis was conducted using R Statistical Software (R Foundation for Statistical Computing, Vienna, Austria). A value of $P<.05$ was considered statistically significant. We report all results but only discuss differences that were both statistically significant $(P<.05)$ and clinically important $(>10 \%){ }^{9,10,12}$

\section{Results}

PC-CMV was evaluated in both active and passive breathing in invasive ventilation; however, only data in active breathing are presented here. The data during passive breathing are shown in the supplementary materials (Fig. S4).

\section{Overall Performance of Leak Compensation}

There was no difference in asynchrony index between PC-CSV and PC-CMV in all tested ventilators during invasive ventilation as well as no difference between PCCSV and PC-CMV in all tested ventilators during NIV. The median asynchrony index decreased as body weight increased in all tested invasive ventilation modes $(P<.001$; Fig. 2, A and B) and NIV modes $(P<.05$; Fig. $2, \mathrm{C}$ and D).

In invasive ventilation modes, all the ventilators except the Avea (without sensor) were triggered by inspiratory flow from the simulator in all scenarios under the baseline leak. In PC-CSV, the asynchrony index was significantly lower with the PB980 and V500 than with the Avea (with sensor), Avea (without sensor), and PB840 in the 0.5 and $1 \mathrm{~kg}$ scenarios and lower than with the Servo-i (with sensor) and Servo-i (without sensor) in the $0.5,1$, and $2 \mathrm{~kg}$ scenarios (Fig. 2A). In PC-CMV, asynchrony index was significantly lower with the PB980 and V500 than with the Servo-i and Avea regardless of the use of a proximal flow sensor in the 1,2, and $4 \mathrm{~kg}$ scenarios except for Avea (without sensor) in the $4 \mathrm{~kg}$ scenario. PB840 showed significantly lower asynchrony index than Avea (with sensor), Servo-i (with sensor), and Servo-i (without sensor) in the 2 and $4 \mathrm{~kg}$ scenarios (Fig. 2B).

In NIV modes, the PB980 was the only ventilator that was triggered by inspiratory efforts of the simulator in all scenarios under the baseline leak. In PC-CSV, the asyn- 

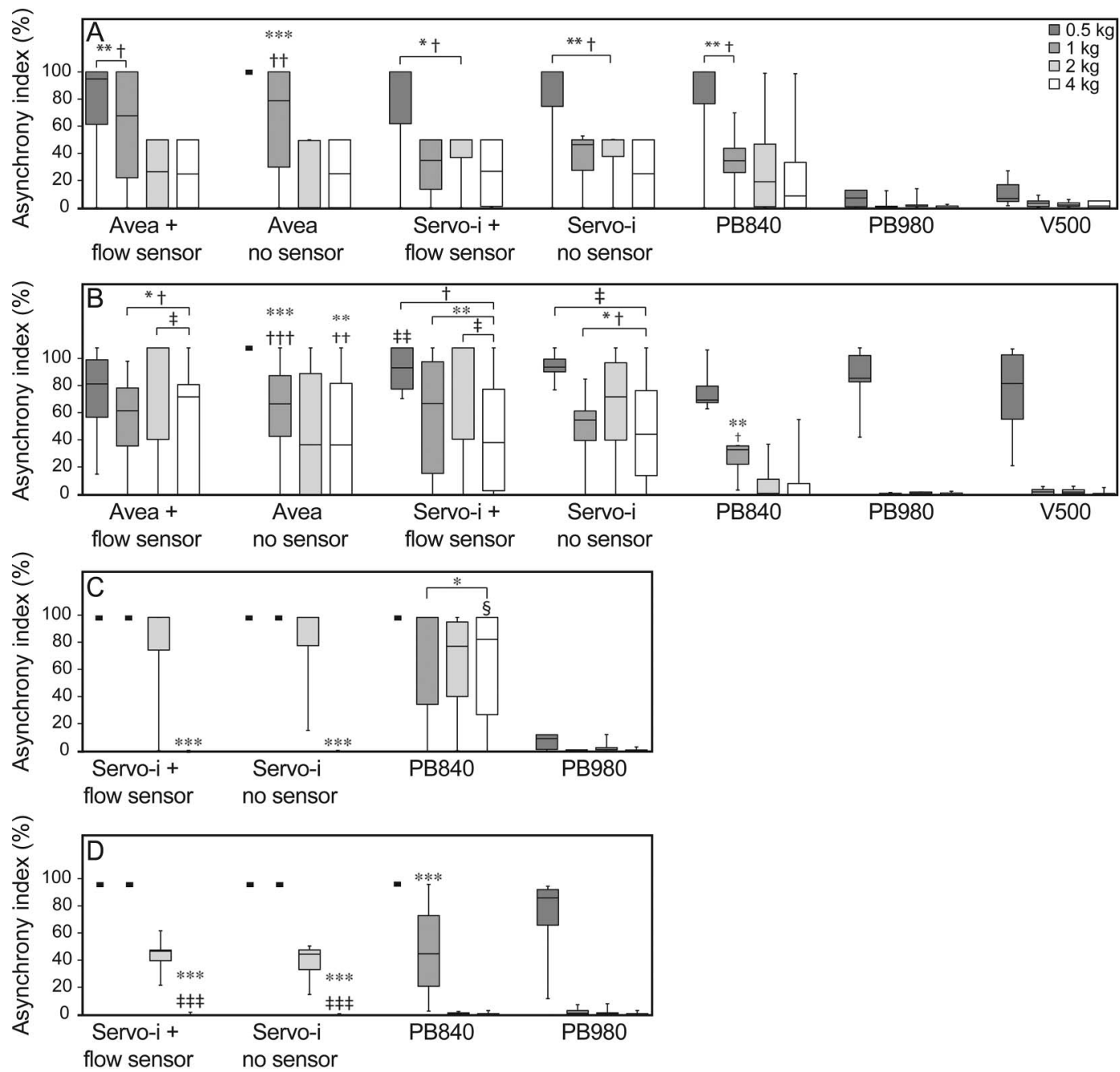

Fig. 2. Asynchrony index (\%) during invasive and noninvasive ventilation (NIV) relative to body weight. A: PC-CSV in invasive ventilation. B: PC-CMV in invasive ventilation. C: PC-CSV in NIV. D: PC-CMV in NIV. Boxes represent the interquartile range 25th and the 75th percentiles; center lines denote the median. Bars represent maximum and minimum values. Data across all leak levels were compared between ventilators at each body weight. A single dash at $100 \%$ indicates non-run, meaning that the ventilator could not be triggered by simulated breaths under the baseline leak, and further leak was not applied (asynchrony index $=100 \%$ ). Avea and Servo-i are shown with and without a proximal flow sensor. ${ }^{*}=P<.05,{ }^{* *}=P<.01,{ }^{\star \star \star}=P<.001$ vs PB980. $\dagger=P<.05, \dagger \dagger=P<.01$, $=P \dagger=P<.001$ vs V500. $\ddagger=$ $P<.05$, 㧊 $=P<.01$, and 㧊 $=P<.001$ vs PB840. $\S=P<.001$ vs Servo-i with and without a flow sensor.

chrony index was significantly lower with PB980 than all other ventilators in the $0.5,1$, and $2 \mathrm{~kg}$ scenarios. The PB840 showed significantly higher asynchrony index in the $4 \mathrm{~kg}$ scenario than the other ventilators (Fig. 2C). In PC-CMV, the asynchrony index was significantly higher with the Servo-i (with sensor) and Servo-i (without sensor) in the $2 \mathrm{~kg}$ scenario than with the PB840 and PB980. The PB840 showed a significantly higher asynchrony index in the $1 \mathrm{~kg}$ scenario than the PB980 (Fig. 2D).

\section{Variable Leaks}

Across all ventilators, the asynchrony index significantly increased as leak level increased except for leak 2 to leak 3 in invasive ventilation modes $(P<.05$; Fig. 3, $\mathrm{A}$ and $\mathrm{B})$. There was no correlation between asynchrony index and leak levels in NIV modes $(P=.96$; Fig. 3, C and $\mathrm{D})$.

In invasive ventilation modes, the asynchrony index was significantly lower with the PB980 and V500 than with the other ventilators at the leak 2 and leak 3 levels except for the PB840 in PC-CMV (Fig. 3, A and B).

In NIV, the asynchrony index during PC-CSV was significantly lower with PB980 than with other ventilators at the leak 1, leak 2, and leak 3 leak levels (Fig. 3C). During PC-CMV, the PB980 outperformed the Servo-i regardless of the use of its proximal flow sensor (Fig. 3D). 

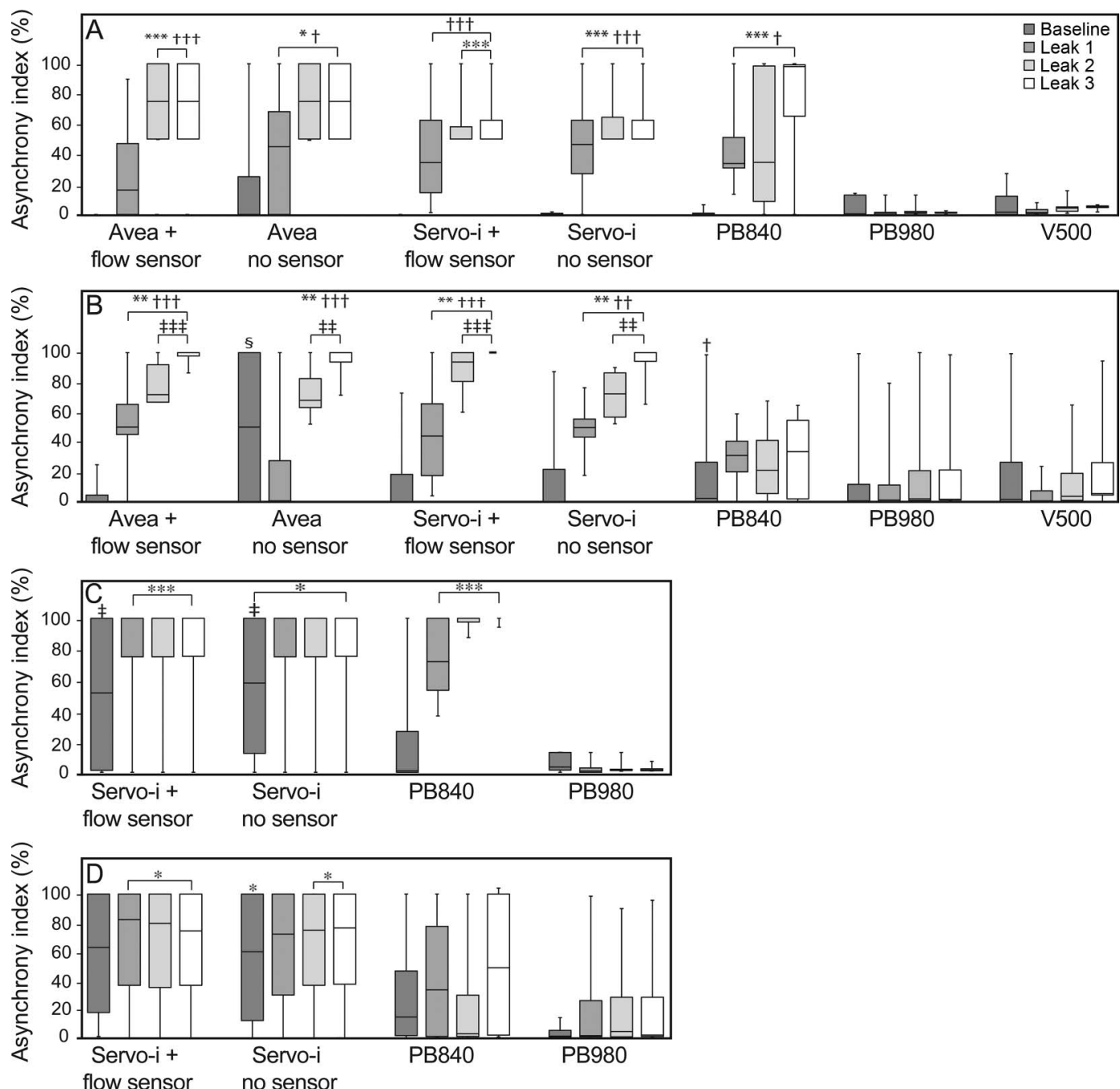

Fig. 3. Asynchrony index (\%) during invasive and noninvasive ventilation (NIV) relative to leak level. A: PC-CSV in invasive ventilation. B: PC-CMV in invasive ventilation. C: PC-CSV in NIV. D: PC-CMV in NIV. Boxes represent the interquartile range (25th and 75th percentiles), and center lines denote the median. Bars represent maximum and minimum values. Data across all body weights were compared between ventilators at each leak level. The Avea and Servo-i are shown with and without a proximal flow sensor. ${ }^{*}=P<.05$, ${ }^{\star \star}=P<.01$, and ${ }^{\star \star \star}$

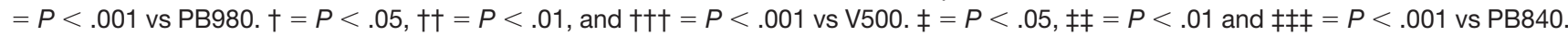
$\S=P<.05$ vs Avea with flow sensor and Servo-i with and without flow sensor.

\section{Cause of Asynchrony}

During invasive ventilation, auto-triggering was the most common cause of asynchrony in PC-CSV (auto-triggering, $17.1 \%$; double-triggering, $13.9 \%$; ineffective efforts, $7.3 \%$; delayed cycling, $0.0 \%$ ), and double-triggering was the most common cause of asynchrony in PC-CMV (auto-triggering, $10.3 \%$; double-triggering, $22.6 \%$; ineffective efforts, $4.6 \%$; delayed cycling, 10.6\%). Between PC-CSV and PC-CMV, no comparison was both statistically significant and clinically important; thus, data from PC-CSV and PC-CMV were pooled (Fig. 4A). Across all body weights, the incidence of both auto-triggering and double-triggering was significantly higher with the Avea (with sensor) $(19.5 \%[P<.01]$ and $34.1 \%$
$[P<.001])$, Servo-i (with sensor) $(19.7 \%[P<.05]$ and $31.6 \%[P<.001])$, and Servo-i (without sensor) $(23.5 \%$ $[P<.001]$ and $26.8 \%[P<.005])$ when compared with the PB980, which had the lowest rates of auto-triggering and double-triggering ( 0.5 and $0.1 \%$, respectively).

During NIV, ineffective efforts were the most frequent cause of asynchrony in PC-CSV (auto-triggering, 1.7\%; double-triggering, $27.7 \%$; ineffective efforts, $70.6 \%$; delayed cycling, $0.0 \%$ ) and PC-CMV (auto-triggering, 2.2\%; double-triggering, $0.4 \%$; ineffective efforts, $80.4 \%$; delayed cycling, $17.0 \%$ ). There was no difference in the rate of each asynchrony between PC-CSV and PC-CMV; thus, data from PC-CSV and PC-CMV were pooled (Fig. 4B). The incidence of ineffective efforts was significantly higher 

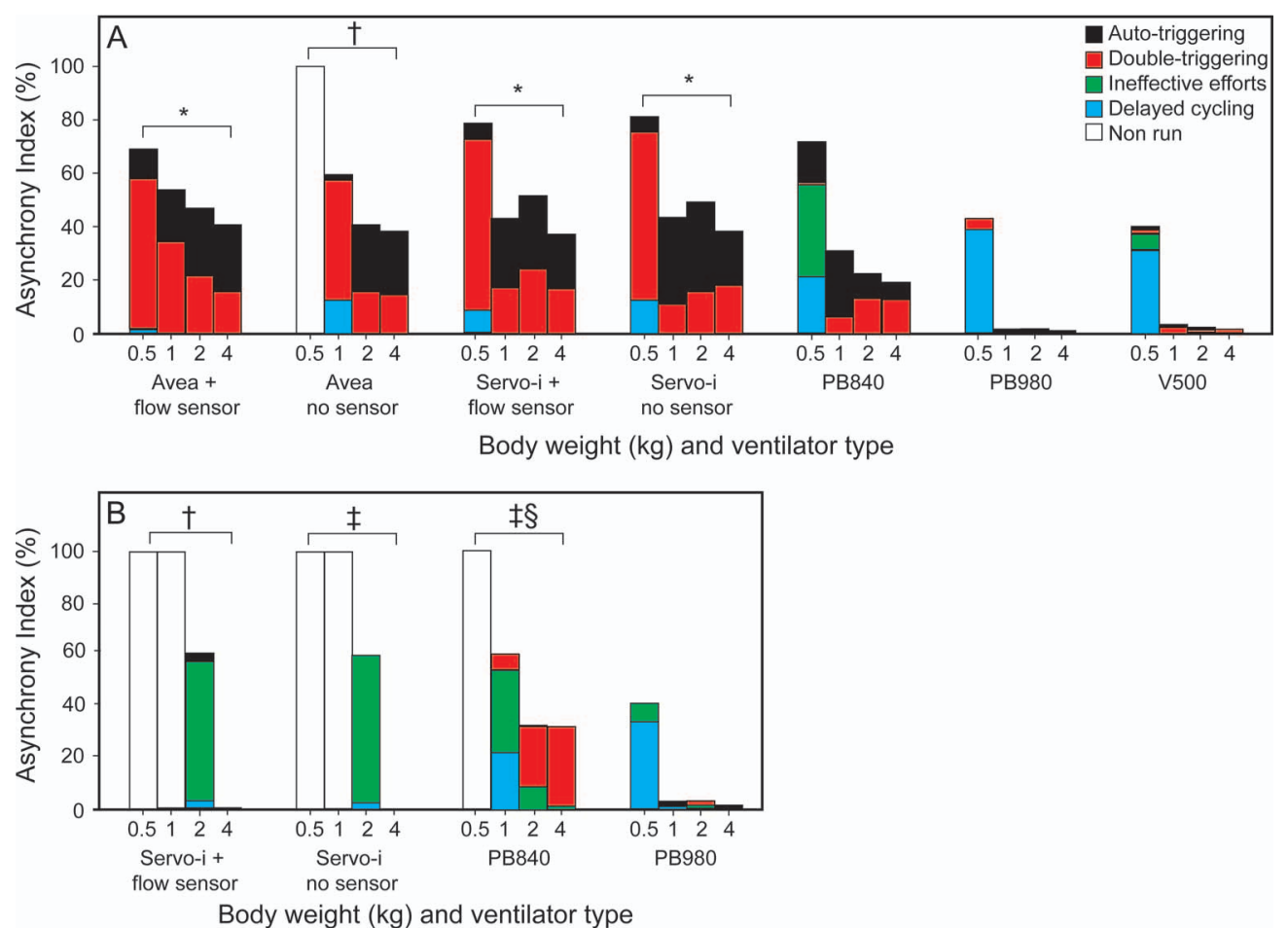

Fig. 4. The cause of asynchrony during invasive $(A)$ and noninvasive ventilation $(B)$ and total asynchrony index. Data from PC-CSV and PC-CMV were pooled. Each asynchrony type across all body weights and leak levels was compared. A white bar (non-run) shows that the ventilator could not be triggered by simulated breaths under the baseline leak and assumed that ineffective efforts occurred in all simulated breaths. ${ }^{*}=P<.05$ vs PB980 for auto-triggering and double-triggering; $\dagger=P<.001$ vs Avea (with sensor) for ineffective efforts; $\ddagger=$ $P<.005$ vs PB980 for ineffective efforts, $\S=P<.005$ vs Servo-i for double-triggering. Each asynchrony was compared with the lowest percentage for that type of asynchrony.

with the Servo-i (with sensor) $(71.4 \%, P<.001)$, Servo-i (without sensor) $(72.2 \%, P<.001)$, and PB840 $(42.9 \%$, $P<.005)$ when compared with PB980, which had the lowest rate of ineffective efforts $(2.5 \%)$. There was no premature cycling in all tested conditions.

\section{Trigger Delay}

Five consecutive, normally triggered breaths were analyzed, but data could not be obtained from runs with frequent asynchronous breaths. Data from PC-CSV and PCCMV were pooled because no clinically important differences were seen. Across all ventilators and leak levels, trigger delay increased as body weight decreased during invasive ventilation $(P<.001$; Fig. 5A) and NIV $(P<.001$; Fig. 5B). During invasive ventilation, trigger delay was unchanged with leak in both PB980 and V500 (Fig. 5A). During NIV, trigger delay increased with leak in PB980 $(P<.001)$ (Fig. 5B).

\section{Ineffective Efforts and Apnea Backup Ventilation During PC-CSV}

Ineffective efforts followed by apnea backup ventilation occurred during PC-CSV (Fig. 6). Backup venti- lation operated during NIV more than during invasive ventilation in the Servo-i (with sensor), Servo-i (without sensor), and PB840, especially in smaller weight scenarios. With the PB980 and V500, sudden ineffective efforts occurred only when leak decreased. Backup ventilation operated with the PB980 but not with the V500. Characteristics of ineffective efforts are summarized in the supplementary materials (Figs. S5 and S6).

\section{Effects of Proximal Flow Sensor}

With Avea and Servo-i, there was no relationship between asynchrony index and the use of a proximal flow sensor in all scenarios during all invasive ventilation and NIV modes (Fig. 2). During invasive ventilation, the use of a proximal flow sensor shortened trigger delay in the Avea $(76.2 \pm 27.7$ [with] vs $103.1 \pm 36.9 \mathrm{~ms}$ [without], $P<.001)$ but not in the Servo-i $(101.3 \pm 28.8$ [with] vs $101.3 \pm 28.8 \mathrm{~ms}$ [without], $P=.94)$. During NIV, trigger delay was not changed in the Servo-i by the use of a proximal flow sensor $(116.4 \pm 15.6$ [with] vs $116.9 \pm 16.7$ ms [without], $P=.82$ ). 


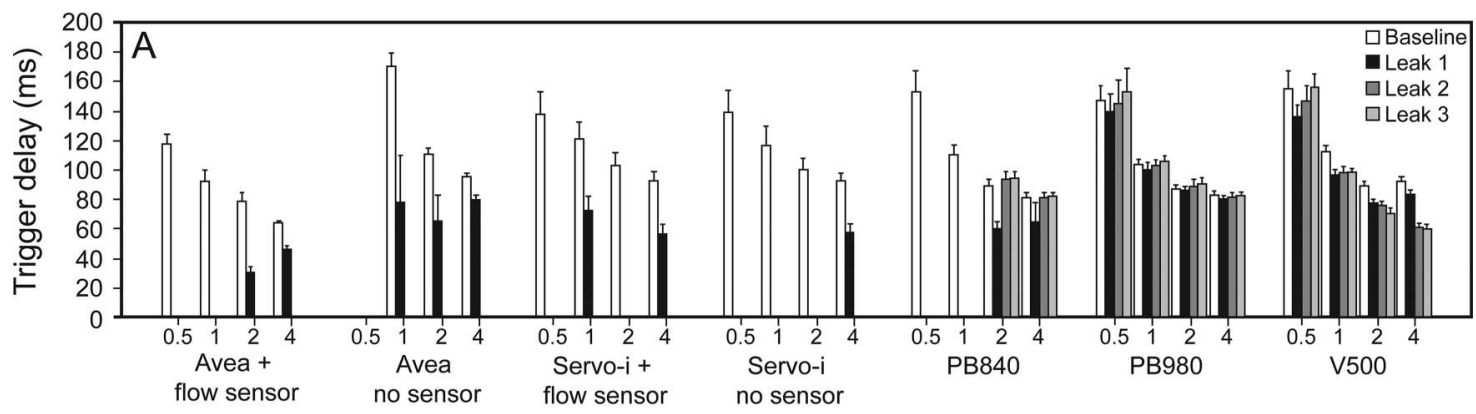

Body weight $(\mathrm{kg})$ and ventilator type

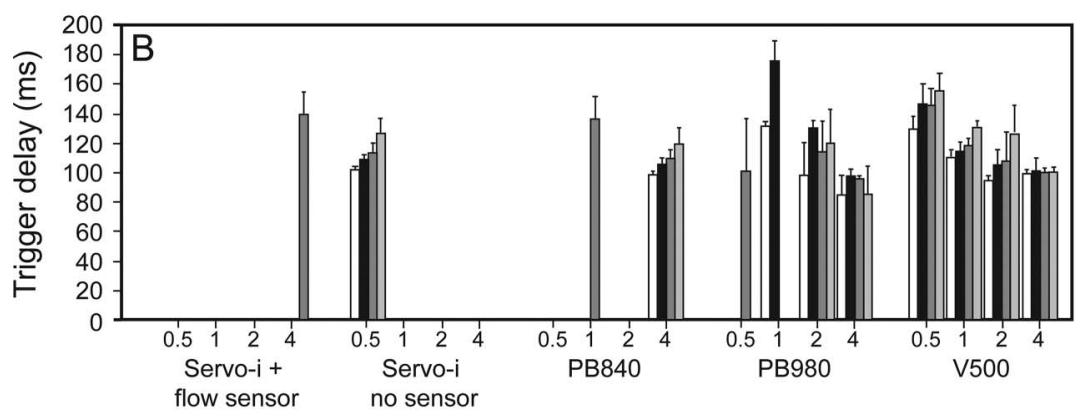

Body weight $(\mathrm{kg})$ and ventilator type

Fig. 5. Change in trigger delay during invasive $(A)$ and noninvasive ventilation $(B)$ with variable leak. Five consecutive, normally triggered breaths were analyzed; thus, no bar means that data could not be obtained due to frequent asynchronous breaths. Data from pressure control continuous spontaneous ventilation (PC-CSV) and pressure control continuous mandatory ventilation (PC-CMV) were pooled. Bars show mean values with SD. As body weight increased, trigger delay shortened in both invasive ventilation $(P<.001)$ and NIV across all ventilators $(P<.01)$.

\begin{tabular}{|c|c|c|c|c|c|c|c|c|c|c|c|c|c|c|c|c|c|c|c|c|c|c|c|c|c|c|c|c|c|}
\hline \multirow{2}{*}{\multicolumn{2}{|c|}{$\begin{array}{l}\text { Ventilator } \\
\text { Scenario }(\mathrm{kg})\end{array}$}} & \multicolumn{4}{|c|}{$\begin{array}{l}\text { Servo-i + } \\
\text { flow sensor }\end{array}$} & \multicolumn{4}{|c|}{$\begin{array}{l}\text { Servo-i } \\
\text { no sensor }\end{array}$} & \multicolumn{4}{|c|}{ PB840 } & \multicolumn{4}{|c|}{ PB980 } & \multicolumn{4}{|c|}{ V500 } & \multicolumn{4}{|c|}{$\begin{array}{c}\text { Avea }+ \\
\text { flow sensor }\end{array}$} & \multicolumn{4}{|c|}{$\begin{array}{c}\text { Avea } \\
\text { no sensor }\end{array}$} \\
\hline & & 0.5 & 1 & 2 & 4 & 0.5 & 1 & 2 & 4 & 0.5 & 1 & 2 & 4 & 0.5 & 1 & 2 & 4 & 0.5 & 1 & 2 & 4 & 0.5 & 1 & 2 & 4 & 0.5 & 1 & 2 & 4 \\
\hline \multirow{4}{*}{$\begin{array}{c}\text { Invasive } \\
\text { PC- } \\
\text { CSV }\end{array}$} & LB & & & & & & & & & $\mathrm{IE}$ & & & & $A R^{*}$ & $\mathrm{AR}^{*}$ & $A R^{\star}$ & & $\mathrm{IE}^{*}$ & & & & & & & & & & & \\
\hline & L1 & & & & & & & & & $\mathrm{A}$ & & & & $\mathrm{AR}^{*}$ & & & & & & & & & & & & & & & \\
\hline & L2 & & & & & & & & & A & & & & $A R^{*}$ & & & & & & & & & & & & & & & \\
\hline & L3 & & & & & & & & & A & & & & & & & & & & & & & & & & & & & \\
\hline \multirow{4}{*}{\begin{tabular}{|c|} 
Non- \\
invasive \\
PC- \\
CSV
\end{tabular}} & LB & & & & & & & $A R$ & & & & & & $A R^{*}$ & & $A R^{*}$ & & & & & & & & & & & & & \\
\hline & L1 & & & A & & & & A & & & A & & & $A R^{*}$ & & & & & & & & & & & & & & & \\
\hline & L2 & & & A & & & & A & & & A & $\mathrm{IE}$ & & $A R^{*}$ & & & & & & & & & & & & & & & \\
\hline & L3 & & & A & & & & $A$ & & & A & $\mathrm{IE}$ & & & & & & & & & & & & & & \multicolumn{4}{|c|}{ Non run" } \\
\hline
\end{tabular}

Fig. 6. Ineffective efforts and operation of apnea ventilation during pressure control continuous spontaneous ventilation (PC-CSV). Servo-i and Avea ventilators tested with and without proximal flow sensors. $A=$ Apnea ventilation was activated, and no spontaneous recovery was seen. $A R=$ Apnea ventilation was activated, and ventilator recovered triggering spontaneously. IE $=$ Ineffective efforts occurred in $>20 \%$ of simulated breaths. $\mathrm{AR}^{\star}=$ Apnea ventilation was activated only when leak decreased to that level. Ventilator recovered triggering spontaneously. IE $\mathrm{I}^{*}=$ Non-sustained ineffective efforts occurred only when leak decreased to that level. Apnea ventilation was not activated. $\mathrm{LB}=$ baseline leak; L1-L3 = leak levels 1-3.

\section{Peak Flow, Peak Pressure, and Expiratory $V_{T}$ During Variable Leak}

Across all ventilators and body weights, peak flow, peak pressure, and expiratory $\mathrm{V}_{\mathrm{T}}$ tended to decrease as the leak increased. Data are shown in the supplementary materials (Figs. S7-S9).

\section{Discussion}

The main findings of this study are as follows. (1) In invasive ventilation modes, the PB980 and V500 showed significantly lower asynchrony index than all other ventilators in $\geq 1 \mathrm{~kg}$ scenarios except for the PB840. (2) In NIV modes, in which only the Servo-i, PB980, and PB840 were 
tested, the PB980 showed a significantly lower asynchrony index than the Servo-i in $\geq 1 \mathrm{~kg}$ scenarios but not the PB840. (3) Auto-triggering and double-triggering were the most common causes of asynchrony during invasive ventilation. (4) Ineffective efforts were the most frequent cause of asynchrony during NIV. (5) The use of the proximal flow sensor did not change the asynchrony index with the Avea and Servo-i; however, it shortened the trigger delay and prevented ineffective efforts with the Avea. (6) During PC-CSV, sudden decrease in leak caused ineffective efforts with the PB980 and V500.

\section{The Incidence of Asynchrony}

We observed a huge variation in the ability of leak compensation among all tested ventilators in both invasive ventilation and NIV. The median asynchrony index was up to $29 \%$ in invasive ventilation, and $48 \%$ in NIV. In view of the fact that an asynchrony index $>10 \%$ has been considered severe asynchrony in previous studies, $4,31,32$ the appropriateness of premature/neonatal patient-triggered modes on many ICU ventilators must be questioned. Vignaux et al clinically investigated asynchronous events during invasive ${ }^{31}$ and noninvasive ${ }^{32}$ pressure support ventilation in infants and children. In both studies, they reported an asynchrony index of $23.9 \%$ in invasive ventilation and $40 \%$ in NIV even after adjustment of the termination criteria. The higher asynchrony index in our study can be explained by the variable intentional leak we set. Also, the premature lung mechanics made it difficult for ventilators to compensate for leaks. We simulated extremely premature infants $(0.5 \mathrm{~kg})$ because the neonatal modes available on ICU ventilators are indicated by the manufacturer as acceptable for this size infant. Our findings are consistent with previous reports that in infants, the asynchrony index tended to increase as body weight decreased, ${ }^{10,23}$ although there are no available data that elucidate these relationships among premature infants.

\section{The Intentional Leak and Asynchrony}

The asynchrony index also increased with leak in invasive ventilation but not in NIV in some of the ventilators tested. Ventilators that did not show this relationship had a greater capacity to compensate for leaks at a higher level. This correlation did not occur during NIV because we observed a high asynchrony index in most scenarios.

Leak has been shown to be a major factor leading to auto-triggering, as we observed in invasive ventilation. 5,6,23 As the level of leak increases, the speed of leak increase is a determining factor in the specific response of a given ventilator. Rapidly developing leaks may require a few breaths before full compensation; thus, the potential of auto-triggering before compensation is maximized. During slowly developing increased leaks, compensation may occur before auto-triggering. However, the frequency of auto-triggering did not increase in proportion to the leak level. This is consistent with a previous clinical study, which demonstrated that auto-triggering occurs regardless of the leak level, once leak flow reaches the trigger threshold. ${ }^{34} \mathrm{We}$ also observed double-triggering more often in PC-CMV than in PC-CSV. This happened because autotriggered breaths were cycled in the middle of the lung model's inspiration, which resulted in a second triggering. Moreover, double-triggering tended to increase with leak in some ventilators during PC-CMV. As leak increased, auto-triggered breaths started before the start of inspiration, resulting in more frequent second triggering. During PC-CSV, inspiratory flow of auto-triggered breaths did not reach termination criteria due to end-inspiratory leak, and inspiration was stopped only when maximum ventilator inspiratory time was reached. Furthermore, prolonged inspiration overlapped the next inspiratory effort and caused ineffective efforts. ${ }^{9}$

On the other hand, if the leak is large enough, the ventilator cannot detect inspiratory efforts, which resulted in ineffective efforts as we observed during NIV. 5,6,22 Further investigation is needed with smaller leak levels to clarify the threshold of auto-triggered breaths during NIV.

\section{Trigger Delay}

Previously, we reported trigger delay of $<100 \mathrm{~ms}$ with ICU ventilators during neonatal ventilation. ${ }^{12}$ At baseline, long trigger delay is probably a result of the lung mechanics during the $0.5 \mathrm{~kg}$ scenario. Trigger delay may theoretically become prolonged as body weight decreases because the lower inspiratory effort reduces the peak inspiratory flow of the lung model or patients. Therefore, the ventilator is less likely to detect inspiratory efforts, and the likelihood of ineffective efforts is increased. ${ }^{22,34}$ Higher airway resistance along with lower compliance impedes the transmission of effort to the ventilator. ${ }^{10}$ Long trigger delays in 0.5 and $1 \mathrm{~kg}$ scenarios caused delayed cycling even in the PB980 and V500 because we used a fixed inspiratory time during PC-CMV. Initial cycling delay of PC-CMV is summarized in the supplementary materials (Fig. S2). In premature ventilation, we may need to pay extra attention to the inspiratory time setting to avoid cycling asynchrony.

As leak increased, trigger delay was markedly shortened in the Servo-i and Avea during invasive ventilation. The decreased trigger delay was directly related to the leak flow finally resulting in auto-triggering. The flow trigger of $0.1-0.3 \mathrm{~L} / \mathrm{min}$ set in each ventilator may have been more sensitive than the range used clinically and thus might have affected the shortening of trigger delay with leak. However, we set sensitivity in all ventilators at the most 


\section{Leak Compensation in ICU Ventilators During Neonatal Ventilation}

sensitive setting that did not result in auto-triggering at baseline settings. It is noteworthy that the PB980 and V500 barely caused auto-triggering at any leak level.

\section{The Influence of the Proximal Flow Sensor on Asynchrony}

Trigger delay was significantly shortened by a proximal flow sensor with the Avea, but not with the Servo-i. In the case of the Avea, improved trigger sensitivity by a proximal flow sensor might prevent ineffective efforts but also caused frequent double-triggering due to insufficient leak compensation. In this study, we did not use the proximal flow sensor with the PB980 because the proximal flow sensor is only used for monitoring of the tidal volume; triggering is controlled by an internal flow sensor. The same concept may also apply to the Servo-i, focusing on the accuracy of the tidal volume measurement rather than on the better trigger sensitivity.

\section{Issues With Leak Compensation}

During PC-CSV, a sudden decrease in leak caused ineffective efforts with the PB980 and V500. Leak compensation algorithms automatically decrease trigger sensitivity according to the amount of leak to avoid auto-triggering. If the leak decreases, trigger sensitivity must rapidly readjust to a more sensitive level. In other words, the new leak plus patient effort is below the prior total leak compensation level, which results in ineffective efforts because of the higher ventilator baseline flow. A slow decrease in leak level may not result in ineffective efforts. However, trigger sensitivity is not always rapidly readjusted. This occurs in ventilators that can compensate for leak at a higher level. When leak flow decreased with the PB980, backup ventilation was activated before normal triggering was resumed. This sudden stop of triggering should be addressed, although its clinical importance is not clear. However, in clinical practice (eg, when the head position is changed), ${ }^{35}$ a marked decrease in leak flow can occur. Most importantly, premature infants have a lower oxygen reserve due to a higher basal metabolic rate than adults. ${ }^{36}$ By setting apnea duration to a very short time interval, this problem can be mostly negated.

\section{Limitations}

There are several limitations to this study. First, this study was not conducted on patients, which raises the question of whether the findings are clinically important. However, it is impossible to control the level of leak in neonatal ventilation, and the bench studies using the ASL 5000 ensure the same experimental conditions for each ventilator. Second, parameters of our lung models poten- tially may not fit all patients with these body weights. Especially in children, morbid lung mechanics of patients with the same body weight generally differ and depend on

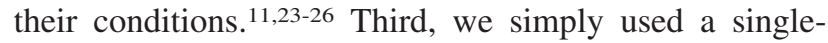
compartment model in the ASL 5000. The ASL 5000 allows simulated non-linear resistance only in the dual-compartment model; thus, our lung models had linear resistance. This may affect the response of the tested ventilators in infants, since infants with lung disease frequently have non-linear resistance. ${ }^{37}$ Fourth, we did not set inspiratory and respiratory resistances separately in our lung models. ${ }^{38}$ Inspiratory and expiratory resistances have different impacts on auto-PEEP because inspiratory resistance affects tidal volume and expiratory resistance affects the time constant. ${ }^{39}$ Finally, we tested only a limited range of leaks and ventilator settings. However, we chose these to represent the range of leak flows that are likely to be encountered in clinical settings.

\section{Clinical Implications}

Our data show that neonatal ventilation is still an issue that requires careful attention. Poor detection of inspiratory effort and an inability to compensate for large leaks make neonatal ventilation difficult, especially for premature infants. Synchronization of the ventilator response with the spontaneous breathing efforts of the neonate is very problematic. This may be the reason why patienttriggered modes are not supported in NIV by ventilators like the V500 and Avea.

\section{Conclusions}

We observed a huge variation in the leak compensation ability among all tested ventilators during both invasive ventilation and NIV. Clinicians should be aware of these differences when they use the ventilators we tested for premature/neonatal ventilation. Although the PB980 and V500 outperformed the other ventilators, further clinical investigation is needed to validate our results.

\section{REFERENCES}

1. De Lima J, Carmo KB. Practical pain management in the neonate. Best Pract Res Clin Anaesthesiol 2010;24(3):291-307.

2. DiBlasi RM. Neonatal noninvasive ventilation techniques: do we really need to intubate? Respir Care 2011;56(9):1273-1294; discussion 1295-1297.

3. Morley CJ, Davis PG, Doyle LW, Brion LP, Hascoet JM, Carlin JB, COIN Trial Investigators. Nasal CPAP or intubation at birth for very preterm infants. N Engl J Med 2008;358(7):700-708.

4. Thille AW, Rodriguez P, Cabello B, Lellouche F, Brochard L. Patient-ventilator asynchrony during assisted mechanical ventilation. Intensive Care Med 2006;32(10):1515-1522.

5. Tobin MJ, Jubran A, Laghi F. Patient-ventilator interaction. Am J Respir Crit Care Med 2001;163(5):1059-1063. 


\section{Leak Compensation in ICU Ventilators During Neonatal Ventilation}

6. Carteaux G, Lyazidi A, Cordoba-Izquierdo A, Vignaux L, Jolliet P, Thille AW, et al. Patient-ventilator asynchrony during noninvasive ventilation: a bench and clinical study. Chest 2012;142(2):367-376.

7. Nava S, Bruschi C, Fracchia C, Braschi A, Rubini F. Patient ventilator interaction and inspiratory effort during pressure support ventilation in patients with different pathologies. Eur Respir J 1997; 10(1):177-183.

8. Tokioka H, Tanaka T, Ishizu T, Fukushima T, Iwaki T, Nakamura Y, Kosogabe Y. The effect of breath termination criterion on breathing patterns and the work of breathing during pressure support ventilation. Anesth Analg 2001;92(1):161-165.

9. Oto J, Chenelle CT, Marchese AD, Kacmarek RM. A comparison of leak compensation in acute care ventilators during non-invasive and invasive ventilation: a lung model study. Respir Care 2013;58(12):20272037.

10. Oto J, Chenelle CT, Marchese AD, Kacmarek RM. A comparison of leak compensation during pediatric noninvasive ventilation: a lung model study. Respir Care 2014;59(2):241-251.

11. Vignaux L, Piquilloud L, Tourneux P, Jolliet P, Rimensberger PC. Neonatal and adult ICU ventilators to provide ventilation in neonates, infants, and children: a bench model study. Respir Care 2014; 59(10): 1463-1475.

12. Marchese AD, Chipman D, de la Oliva P, Kacmarek RM. Adult ICU ventilators to provide neonatal ventilation: a lung model study. Intensive Care Med 2009;35(4):631-638.

13. Iyer NP, Chatburn R. Evaluation of a nasal cannula in noninvasive ventilation using a lung simulator. Respir Care 2015;60(4):508-512.

14. Sivieri EM, Gerdes JS, Abbasi S. Effect of HFNC flow rate, cannula size, and nares diameter on generated airway pressures: an in vitro study. Pediatr Pulmonol 2013;48(5):506-514.

15. Volsko TA, Fedor K, Amadei J, Chatburn RL. High flow through a nasal cannula and CPAP effect in a simulated infant model. Respir Care 2011;56(12):1893-1900.

16. Gappa M, Pillow JJ, Allen J, Mayer O, Stocks J. Lung function tests in neonates and infants with chronic lung disease: lung and chestwall mechanics. Pediatr Pulmonol 2006;41(4):291-317.

17. Snepvangers Y, de Winter JP, Burger H, Brouwers H, van der Ent CK. Respiratory outcome in preterm ventilated infants: importance of early respiratory system resistance. Eur J Pediatr 2004;163(7):378-384.

18. Lui K, Lloyd J, Ang E, Rynn M, Gupta JM. Early changes in respiratory compliance and resistance during the development of bronchopulmonary dysplasia in the era of surfactant therapy. Pediatr Pulmonol 2000;30(4):282-290.

19. Baraldi E, Filippone M, Trevisanuto D, Zanardo V, Zacchello F. Pulmonary function until two years of life in infants with bronchopulmonary dysplasia. Am J Respir Crit Care Med 1997;155(1):149-155.

20. Brar G, Geiss D, Brion LP, Rios A. Respiratory mechanics in very low birth weight infants during continuous versus intermittent gavage feeds. Pediatr Pulmonol 2001;32(6):442-446.

21. Schmalisch G, Wilitzki S, Roehr CC, Proquitté H, Bührer C. Differential effects of immaturity and neonatal lung disease on the lung function of very low birth weight infants at 48-52 postconceptional weeks. Pediatr Pulmonol 2013;48(12):1214-1223.

22. Gerhardt T, Hehre D, Feller R, Reifenberg L, Bancalari E. Pulmonary mechanics in normal infants and young children during first 5 years of life. Pediatr Pulmonol 1987;3(5):309-316.
23. Fauroux B, Leroux K, Desmarais G, Isabey D, Clément A, Lofaso F, Louis B. Performance of ventilators for noninvasive positive-pressure ventilation in children. Eur Respir J 2008;31(6):1300-1307.

24. Harikumar G, Moxham J, Greenough A, Rafferty GF. Measurement of maximal inspiratory pressure in ventilated children. Pediatr Pulmonol 2008;43(11):1085-1091.

25. Curzi-Dascalova L, Peirano P, Morel-Kahn F. Development of sleep states in normal premature and full-term newborns. Dev Psychobiol 1988;21(5):431-444.

26. Kapasi M, Fujino Y, Kirmse M, Catlin EA, Kacmarek RM. Effort and work of breathing in neonates during assisted patient-triggered ventilation. Pediatr Crit Care Med 2001;2(1):9-16.

27. Bernstein G, Knodel E, Heldt GP. Airway leak size in neonates and autocycling of three flow-triggered ventilators. Crit Care Med 1995; 23(10):1739-1744

28. Mahmoud RA, Proquitté H, Fawzy N, Bührer C, Schmalisch G. Tracheal tube airleak in clinical practice and impact on tidal volume measurement in ventilated neonates. Pediatr Crit Care Med 2011; 12(2):197-202.

29. Ramanathan R. Nasal respiratory support through the nares: its time has come. J Perinatol 2010;30(Suppl):S67-S72

30. Chatburn RL, El-Khatib M, Mireles-Cabodevila E. A taxonomy for mechanical ventilation: 10 fundamental maxims. Respir Care 2014; 59(11):1747-1763.

31. Vignaux L, Grazioli S, Piquilloud L, Bochaton N, Karam O, Jaecklin $\mathrm{T}$, et al. Optimizing patient-ventilator synchrony during invasive ventilator assist in children and infants remains a difficult task. Pediatr Crit Care Med 2013;14(7):e316-e325.

32. Vignaux L, Grazioli S, Piquilloud L, Bochaton N, Karam O, Levy-Jamet $\mathrm{Y}$, et al. Patient-ventilator asynchrony during noninvasive pressure support ventilation and neurally adjusted ventilatory assist in infants and children. Pediatr Crit Care Med 2013; 14(8):e357-e364.

33. Vignaux L, Vargas F, Roeseler J, Tassaux D, Thille AW, Kossowsky MP, et al. Patient-ventilator asynchrony during non-invasive ventilation for acute respiratory failure: a multicenter study. Intensive Care Med 2009;35(5):840-846.

34. Ferreira JC, Chipman DW, Hill NS, Kacmarek RM. Bilevel vs ICU ventilators providing noninvasive ventilation: effect of system leaks: a COPD lung model comparison. Chest 2009;136(2):448-456.

35. Finholt DA, Henry DB, Raphaely RC. Factors affecting leak around tracheal tubes in children. Can Anaesth Soc J 1985;32(4):326-329.

36. Rimensberger PC, Hammer J. Mechanical ventilation in the neonatal and pediatric setting. In: Tobin MJ, editor. Principles and practice of mechanical ventilation, 3rd edition. New York: McGraw-Hill Medical Publishing Division; 2012:573-579.

37. Nikischin W, Gerhardt T, Everett R, Bancalari E. A new method to analyze lung compliance when pressure-volume relationship is nonlinear. Am J Respir Crit Care Med 1998;158(4):1052-1060.

38. Miller MJ, DiFiore JM, Strohl KP, Carlo WA, Martin RJ. Effects of $\mathrm{CO}_{2}$ rebreathing on pulmonary mechanics in premature infants. J Appl Physiol 1991;70(6):2582-2586.

39. Blanch L, Bernabé F, Lucangelo U. Measurement of air trapping, intrinsic positive end-expiratory pressure, and dynamic hyperinflation in mechanically ventilated patients. Respir Care 50(1):110-123, 2005; discussion 123-124.

This article is approved for Continuing Respiratory Care Education credit. For information and to obtain your CRCE

(free to AARC members) visit www.rcjournal.com

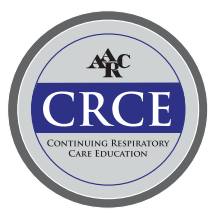

